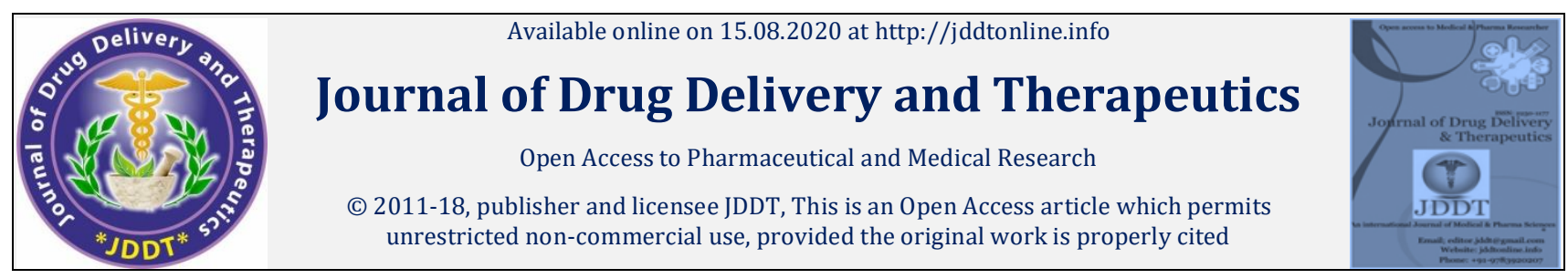

Open $\odot$ Access

Research Article

\title{
Nephroprotective activity of ethanolic extract of Cinnamomum zeylanicum bark against acetaminophen induced nephrotoxicity in albino rats
}

\author{
Md Qyamuddin'* , Pawan Kumar'1, Sokindra Kumar², Md Rafiul Haque ${ }^{3}$ \\ ${ }^{1}$ School of Pharmacy and Medical Science, Singhania University, Jhunjhunu, Rajasthan, India \\ ${ }^{2}$ Kharvel Subharti College of Pharmacy, Swami Vivekanand Subharti University, Meerut, UP, 250005, India \\ ${ }^{3}$ HIMT College of Pharmacy, Department of Pharmacognosy, Knowledge park1, Gr. Noida (U.P), India
}

\begin{abstract}
Objective: To investigate the protective activity of ethanolic extract of Cinnamomum zeylanicum bark (EECZB) against acetaminophen induced nephrotoxicity in albino rats.

Methods: Wistar albino rats (150-200 g) were divided into six groups and toxicity was induced by acetaminophen (750 mg/kg) for 10 days. 100 and $200 \mathrm{mg} / \mathrm{kg}$ of ethanolic extract of Cinnamomum zeylanicum bark and $100 \mathrm{mg} / \mathrm{kg}$ of silymarin as a reference standard was treated to rats $2 \mathrm{~h}$ before acetaminophen administration. Various biochemical parameters like serum urea, serum creatinine, uric acid and total protein levels and antioxidant activity were determined. Histopathological analyses of kidney injury were also determined.

Result: Treatment with ethanolic extract of Cinnamomum zeylanicum bark $(100,200 \mathrm{mg} / \mathrm{kg}$, bw) significantly (p<0.001, p $<0.01)$ decreased serum urea and serum creatinine as compared with acetaminophen rats. Decreased levels of uric acid and total protein were also significantly restored with extract of Cinnamomum zeylanicum bark treatment. Silymarin significantly $(\mathrm{p}<0.001)$ decreased serum urea and serum creatinine as compared with acetaminophen rats. It is also significantly restored the altered levels of SOD, CAT and GSH in kidney tissu e. Apart from these, extract of Cinnamomum zeylanicum bark treatment also reduced histopathological alteration induced by acetaminophen in kidney.
\end{abstract}

Conclusion: It was observed that ethanolic extract of Cinnamomum zeylanicum bark has a significant nephroprotective activity against acetaminophen induced nephrotoxicity in albino rats.

Keywords: Cinnamomum zeylanicum, acetaminophen, nephroprotective activity.

Article Info: Received 10 June 2020; Review Completed 17 July 2020; Accepted 26 July 2020; Available online 15 August 2020

\section{Cite this article as:}

Qyamuddin M, Kumar P, Kumar S, Haque MR, Nephroprotective activity of ethanolic extract of Cinnamomum zeylanicum bark against acetaminophen induced nephrotoxicity in albino rats, Journal of Drug Delivery and Therapeutics. 2020; 10(4-s):80-86 http://dx.doi.org/10.22270/jddt.v10i4-s.4292

\section{*Address for Correspondence:}

Md Qyamuddin, School of Pharmacy and Medical Science, Singhania University, Pacheribari, Jhunjhunu, Rajasthan-333515 India

\section{INTRODUCTION}

Acetaminophen (N-acetyl-p-aminophenol; APAP) is one of safest and most frequently used, non-prescription, over the counter, analgesic \& antipyretic drug1,2,3. A study conducted in USA stated that acetaminophen was found to be associated with more than $10,00,00$ cases of poisoning, 56000 visited to emergency department, 26000 hospitalization and 450 deaths a year ${ }^{3}$. The drug is safe at therapeutic doses ${ }^{4}$. However over dose may result to potentially fatal hepatic and renal damage in human and experimental animals ${ }^{5}, 6$, 7. Initially APAP exerts its toxicity by forming a reactive intermediate $\mathrm{N}$-acetyl-pbenzoquinonimine (NAPQI) by cytochrome P-450, which at therapeutic dose gets eliminated by conjugation with glutathione sulfhydryl (GSH). Acetaminophen overdosing may result in the depletion of cellular $\mathrm{GSH}$, leading to binding of NAPQI to cellular protein and thus initiating the lipid peroxidation, both of which can contribute to hepatic and renal damage 8,9 . This cascade further provokes inflammatory signals and extends the injury, resulting in tubular cell death/ acute renal failure ${ }^{10}$. The presence of excess NAPQI also leads to oxidative stress leading to liver damage ${ }^{11}$. A similar mechanism was proposed to be nephrotoxicity of acetaminophen6,12,13. Nephrotoxicity due to acetaminophen overdose is found to be relatively less common than hepatotoxicity. Also acute renal failure can be seen even in the absence of liver injury 14 . The acetaminophen induced kidney damage may include acute tubular necrosis, increase creatinine levels, and decrease in glomerular filtration rate (GFR). Tubular cell injury is found to one of the main feature in acetaminophen induced renal failure along with phosphaturia and low molecular-weight 
proteinuria is represented as the functional evidence of proximal tubular injury ${ }^{15}$.

Cinnamomum zeylanicum (family Lauraceae) bark is commonly known as cinnamon, widely used as spice, condiment and flavouring agent. It is a tropical evergreen tree, native to Srilanka East and Middle Asia called differently in different languages such as dalchini in Hindi, carnelle in French, kaneel in German, canela in Spanish and yook gway in Chinese ${ }^{16,17}$. The bark is bitter, sweet, aromatic, astringent, aphrodisiac, deodorant, stimulant, expectorant and diuretic and carminative ${ }^{18}$. Cinnamon bar is a very common culinary spice and used in candy, toothpaste and perfumes. The cinnamon barks contains volatile oils (14\%) of cinnamaldehyde (60\%), euginol (10\%) and trans-cinnamic acid (51\%), phenolic compounds, tannin, catechins and proanthocyanidians: monoterpines and sesquiterpines, mucilage; starch, resin, sugar and trace of Coumadin ${ }^{19}$. The principal constituents are cinnamaldehyde 20 . Traditional medicine reports its uses as antitussive, antiarthritis, antimicrobial, antifungal, antioxidant, anti-inflammatory and antidiabetic ${ }^{21}$, also as component of various compounds used in Indian Ayurvedic medicine $^{19}$. In the present study we investigate the protective activity of ethanolic extract of Cinnamomum zeylanicum bark on acetaminophen induced nephrotoxicity in albino rats.

\section{MATERIAL AND METHODS}

\section{Chemical}

Acetaminophen was obtained from gift sample from Arbro pharmaceutical company. Assay for kidney marker enzyme such as urea, creatinine, uric acid and total protein were purchase from Erba diagnostic Mannhein, Germany. All other reagents used in this experimental study were according to analytical grade.

\section{Plant material}

The Cinnamomum zeylanicum bark was procured from local market in old Delhi. The bar was identified and authenticated by Dr. Sunita Garg, CSIR-NISCAIR New Delhi. A voucher specimen (Ref. No. NISCAIR/RHMD/CONSULT/ 2018/3261-62) has been deposited in herbarium of CSIRNISCAIR. New Delhi.

\section{Preparation of extract}

The Cinnamomum zeylanicum bark was first dried then powdered and the extract was obtained using ethanol in Soxhlet apparatus for 8 hours. The extract was then filtered and evaporated to dryness at $50^{\circ} \mathrm{C}$ in a water bath and the final dry extract was stored in dark at $-20{ }^{\circ} \mathrm{C}$ until used for the experiments. The percentage yield of extract was $43 \%$.

\section{Preliminary phytochemical study}

Ethanolic extract of cinnamomum bark were analysed for their chemical constituents. A preliminary phytochemical analysis was carried out to determine the phytochemical constituents which were responsible for the nephroprotective activity. Some of these methods are as follow 22,23 .

\section{Animals}

Adult albino wistar rats (150-200 g) of either sex were obtained from All India Institute of Medical Science (AIIMS), New Delhi, India. The animals were isolated in cages which was maintained at $24 \pm 2^{\circ} \mathrm{C}$ temperature and a relative humidity of $45-55 \%$ with $12: 12 \mathrm{~h}$ light/dark cycle. The animals were provided with standard pellet feed with ad libitum drinking water. The experimental protocol was approved by the institutional animal ethical committee (IAEC) of HIMT College of Pharmacy (Reg. No. 1377/PO/Re/S/10/CPCSEA), Gautam Budh Nagar, Uttar Pradesh, India and performed in accordance with the guideline of committee for the purpose of control and supervision of animals (CPCSEA), New Delhi.

\section{Acute oral toxicity}

An acute oral toxicity of ethanolic extract of Cinnamomum zeylanicum bark was determined in albino rats according to OECD Guideline No. $423{ }^{24}$. The animals were provided with access to water but not food overnight, after which the ethanolic extract of Cinnamomum zeylanicum bark was administered orally in $1 \%$ carboxy methyl cellulose (CMC) at a dose of 500, 1000 and $2000 \mathrm{mg} / \mathrm{kg}$ body weight. Rats were observed for initially $4 \mathrm{~h}$ after the administration of drug after that once daily during the following day. The behavioural change observed for hyperactivity, ataxia, tremors, convulsion, salivation, diarrhoea, sleep and coma. The total observation period for eventually mortality was 14 days. No mortality was observed upto $2000 \mathrm{mg} / \mathrm{kg}$. One tenth and one twentieth of the maximum tolerated dose $(2000 \mathrm{mg} / \mathrm{kg}$ ) of extract was selected for the study.

\section{Acetaminophen induced toxicity and drug treatment schedule}

The selection of dose of acetaminophen was based on studies carried out by previous 25.26,27,28. Silymarin was administered to a rat orally at a dose of $100 \mathrm{mg} / \mathrm{kg}{ }^{29}$. Fasted rats were randomly divided into seven groups of six animals in each group. Group I served as control group and treated with $1 \%$ CMC $(1 \mathrm{ml} / \mathrm{kg}$, p.o) daily for 10 days. Group II served as toxic and treated with acetaminophen $(750 \mathrm{mg} / \mathrm{kg}$, p.o) suspended in 1\% CMC three alternative days for 10 days. Group III served as perse and was given only Cinnamomum zeylanicum bark extract $(100 \mathrm{mg} / \mathrm{kg} \mathrm{b.w)}$ daily for 10 days. Group IV and Group V served as treatment group and were treated with Cinnamomum zeylanicum bark extract $(100,200 \mathrm{mg} / \mathrm{kg}$, p.o) daily for 10 days. Group VI served as standard group and was treated as silymarin (100 $\mathrm{mg} / \mathrm{kg}$ ) orally for 10 days. Group II, IV, V and VI was administered with acetaminophen suspension $(750 \mathrm{mg} / \mathrm{kg}$, p.o) after 2 h administered of Cinnamomum zeylanicum bark extract for three alternative days for 10 days.

After completion of treatment all the animals were kept fasted for $12 \mathrm{~h}$, followed by collection of blood samples from retro orbital plexus under ether anaesthesia. The animals were then sacrificed and collection of their kidney was done precisely. The analysis for biochemical parameter was performed with blood samples whereas estimation of antioxidants and histopathological studies were done using the kidney samples.

\section{Biochemical Analysis}

Blood was drawn by puncturing the retro-orbital plexus under diethyl ether anaesthesia using heparin coated capillaries. Serum was separated by centrifugation at 3000 rpm for $15 \mathrm{~min}$, stored at $-20{ }^{\circ} \mathrm{C}$ until analysis. Serum sample were used to determine urea, creatinine, uric acid, and total protein using commercially available assay kits (Erba diagnostic Mannheim, Germany).

\section{Preparation of kidney homogenate}

Kidney tissues were homogenized in $10 \% \mathrm{w} / \mathrm{v} 0.1 \mathrm{M}$ phosphate buffer and centrifuged at $10000 \mathrm{rpm}$ for $15 \mathrm{~min}$ in homogenizer. The supernatant was used to estimate superoxide dismutase, catalase and reduced glutathione. 
Determination of superoxide dismutase (SOD, catalase (CAT) and reduced glutathione (GSH).

The enzymatic antioxidant was determined by estimating superoxide dismutase ${ }^{30}$, Catalase ${ }^{31}$ and non-enzymatic antioxidant by reduced glutathione 32 .

\section{Histopathological studies}

After experimental period animals were sacrificed, kidney removed immediately, sliced and washed in saline and transfer into $10 \%$ formalin solution, after one week tissue were dehydrated with ethanol solutions, embedded in paraffin, cut into $5 \mu \mathrm{m}$ section, stained with haematoxylin and eosin (H \& E) and then observed under microscope.

\section{Statistical analysis}

All data is expressed as Mean \pm Standard Error of the mean (SEM) and statistical analysis was performed using Graphpad prism-5 software (Graphpad Software). The statistical assessment was done using one-way analysis of variance (ANOVA) followed by Tukey multiple compare tests considering $\mathrm{p}<0.05$ as statistically significant.

\section{RESULTS}

\section{Preliminary Phytochemical analysis}

Preliminary phytochemical studies revealed the presence of alkaloid, saponin, tannin, terpanoid, flavonoids and phenol

\section{Acute oral toxicity}

The ethanolic extract of Cinnamomum zeylanicum was subjected to acute toxicity testing in albino rats and was monitored for $24 \mathrm{~h}$. The ethanolic extract of Cinnamomum zeylanicum bark has found to be not causing any mortality up to $2000 \mathrm{mg} / \mathrm{kg}$ and hence $1 / 10^{\text {th }}$ and $1 / 20^{\text {th }}$ of the maximum dose i.e 100 and $200 \mathrm{mg} / \mathrm{kg}$ were finalised for the present experiment.
Effect of Ethanolic extract of Cinnamomum zeylanicum bark (EECZB) on Serum Urea, Uric acid, creatinine, total protein, superoxide dismutase, catalase and reduced glutathione.

Serum blood urea level and creatinine level were significantly $(\mathrm{p}<0.001)$ increased where as serum uric acid and total protein level were significantly $(\mathrm{p}<0.001)$ decreased in APAP treated rats as compare to nonexperimental rats. The administration of ethanolic extract of Cinnamomum zeylanicum bark (EECZB) at different dose $100 \mathrm{mg} / \mathrm{kg}$ and $200 \mathrm{mg} / \mathrm{kg}$, orally for 10 days were significantly $(\mathrm{p}<0.01, \mathrm{p}<0.001)$ decreased in serum urea and creatinine levels whereas serum uric acid levels and total protein were significantly $(\mathrm{p}<0.01, \mathrm{p}<0.001)$ decreased as compared with APAP rats. When compared with APAP treated rats the serum blood urea and creatinine levels were significantly $(\mathrm{p}<0.001)$ decreased in silymarin $(100 \mathrm{mg} / \mathrm{kg}$, b.w) treated rats whereas the levels of serum uric acid and total protein were significantly $(\mathrm{p}<0.001)$ increased. However serum urea, creatinine and uric acid did not differ significantly in normal as well as per se treated rats (Table1).

Administration of APAP resulted in significant $(\mathrm{p}<0.001)$ decrease in superoxide dismutase, catalase and reduced glutathione level in APAP experimental rats as compared to non experimental rats. Treatement with EECZB at different dose 100, $200 \mathrm{mg} / \mathrm{kg}$, bw, showed significant $(\mathrm{p}<0.01, \mathrm{p}<0.001)$ decreases in elevated level of superoxide dismutase, catalase and reducedglutathione as compared to APAP treated rats. Administration of silymarin as reference standard showed significant $(\mathrm{p}<0.001)$ increased in the level of superoxide dismutase, catalase and reduced glutathione as compared to APAP treated rats. The level of superoxide dismutase, catalase and reduced glutathione do not significantly differ in per se group as compare to normal group (Table:2).

Table 1: Effect of ethanolic extract of Cinnamomum zeylanicum bark (EECZB) on serum urea, creatinine, uric acid and total protein.

\begin{tabular}{|l|c|c|c|c|}
\hline Treatment & Urea $(\mathrm{mg} / \mathrm{dl})$ & Creatinine $(\mathrm{mg} / \mathrm{dl})$ & Uric acid(mg/dl) & Total protein P(mg/dl) \\
\hline Normal control & $34.1 \pm 1.43$ & $0.79 \pm 0.01$ & $3.01 \pm 0.02$ & $7.79 \pm 0.01$ \\
\hline APAP Toxic & $78.5 \pm 0.96^{\$ \$}$ & $1.88 \pm 0.01^{\$ \$}$ & $1.04 \pm 0.02^{\$ \$}$ & $5.87 \pm 0.02^{\$ \$}$ \\
\hline EECZB $(100 \mathrm{mg} / \mathrm{kg})$ & $38.6 \pm 1.86$ & $0.80 \pm 0.01$ & $2.94 \pm 0.02$ & $7.74 \pm 0.01$ \\
\hline EECZB $((100 \mathrm{mg} / \mathrm{kg})+$ APAP & $68 \pm 0.5^{* * *}$ & $1.77 \pm 0.02^{* *}$ & $1.16 \pm 0.02^{* * *}$ & $5.75 \pm 0.02^{* *}$ \\
\hline EECZB) $(200 \mathrm{mg} / \mathrm{kg})+A P A P$ & $59.7 \pm 0.96^{* * *}$ & $1.44 \pm 0.01^{* * *}$ & $1.96 \pm 0.01^{* * *}$ & $6.31 \pm 0.02^{* * *}$ \\
\hline Silymarin((100)+APAP & $51.1 \pm 1.04^{* * *}$ & $1.26 \pm 0.02^{* * *}$ & $2.34 \pm 0.02^{* * *}$ & $6.65 \pm 0.03^{* * *}$ \\
\hline
\end{tabular}

All values were expressed as mean \pm SEM for six rats in each group. $\$ \$ p<0.001$ as compared to control groups, ${ }^{* * *}$ p $<0.001,{ }^{*} p$ $<0.05,{ }^{* *} \mathrm{p}<0.01$ as compared to APAP groups

Table 2: Effect of ethanolic extract of Cinnamomum zeylanicum bark (EECZB) on kidney antioxidant status.

\begin{tabular}{|l|c|c|c|}
\hline Treatment & Superoxide dismutase $(\mathrm{U} / \mathrm{mg})$ & Catalase $(\mathrm{U} / \mathrm{mg})$ & Reduced glutathione (ug/mg protein) \\
\hline Normal control & $9.83 \pm 0.10$ & $39 \pm 0.44$ & $33.3 \pm 0.42$ \\
\hline APAP Toxic & $5.25 \pm 0.05^{\$ \$}$ & $20.2 \pm 0.40^{\$ \$}$ & $22.6 \pm 0.34^{\$ \$}$ \\
\hline EECZB $(100 \mathrm{mg} / \mathrm{kg})$ & $10.2 \pm 1.15$ & $39.6 \pm 0.42$ & $33.7 \pm 0.45$ \\
\hline EECZB $((100 \mathrm{mg} / \mathrm{kg})+$ APAP & $6.03 \pm 0.07^{* *}$ & $23.7 \pm 0.21^{* * *}$ & $24.7 \pm 0.23^{* *}$ \\
\hline EECZB) $(200 \mathrm{mg} / \mathrm{kg})+$ APAP & $7.36 \pm 0.06^{* * *}$ & $28.9 \pm 0.31^{* * *}$ & $27.1 \pm 0.21^{* * *}$ \\
\hline Silymarin $((100)+$ APAP & $8.01 \pm 0.11^{* * *}$ & $35.2 \pm 0.30^{* * *}$ & $29.3 \pm 0.23^{* * *}$ \\
\hline
\end{tabular}

All values were expressed as mean \pm SEM for six rats in each group. $\$ \$ p<0.001$ as compared to control groups, ${ }^{* * *} p<0.001,{ }^{*} p$ $<0.05,{ }^{* *}$ p $<0.01$ as compared to APAP groups 


\section{Histopathological studies}

The Histopathological examination revealed that the normal control rats and those treated with EECZB only showed normal renal tubule and glomeruli (figure: $1 \mathrm{~A}, 1 \mathrm{C}$ ). However the rats treated with APAP only showed severe dilation of renal tubule, infiltration of bowman space and damage of podocyte (figure: $1 \mathrm{~B})$. In contrast the rat treated with APAP and EECZB (100, $200 \mathrm{mg} / \mathrm{kg}$ b.w) show less neutrofil infiltration in glomeruli and less bowman space (figure: 1D), mild dilation, very less infiltration in bowman space and mild podocyte damage (figure: 1E) compared to APAP treated rats. The rats treated with Silymarin show normal distal \& proximal tubules, glomeruli and bowman space (figure: $1 \mathrm{~F}$ )

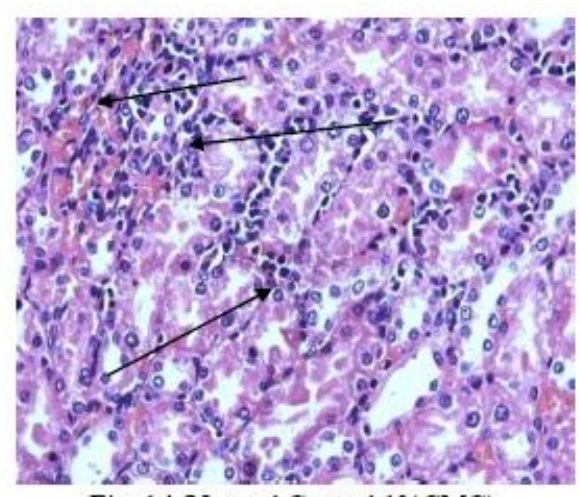

Fig: 1A(Normol Control, $1 \% \mathrm{CMC})$

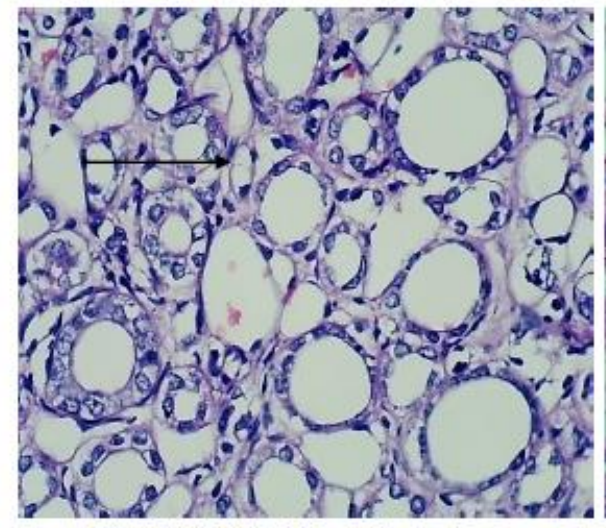

Fig:1C(EECZB $100 \mathrm{mg} / \mathrm{kg}$, bw)

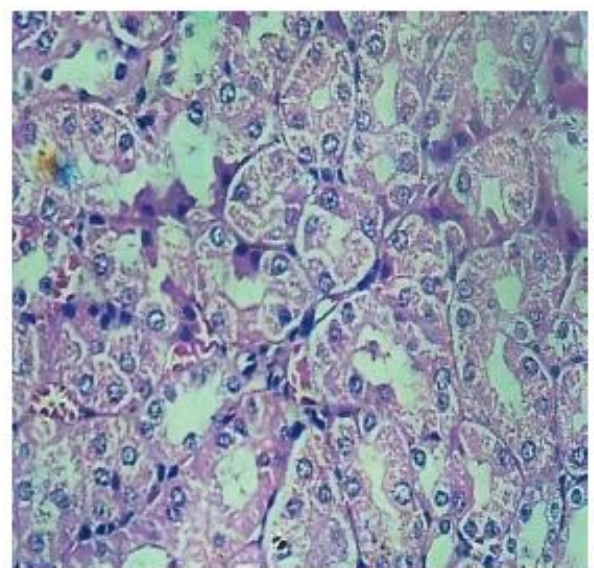

Fig:1E (EECZB $(200 \mathrm{mg} / \mathrm{kg})+\mathrm{APAP})$

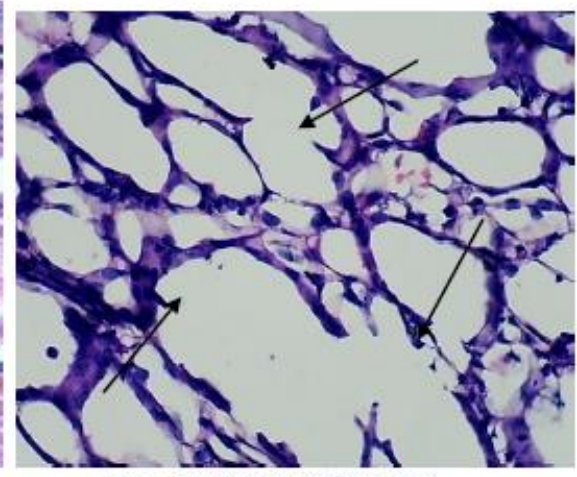

Fig: 1B(APAP, $750 \mathrm{mg} / \mathrm{kg}$ )

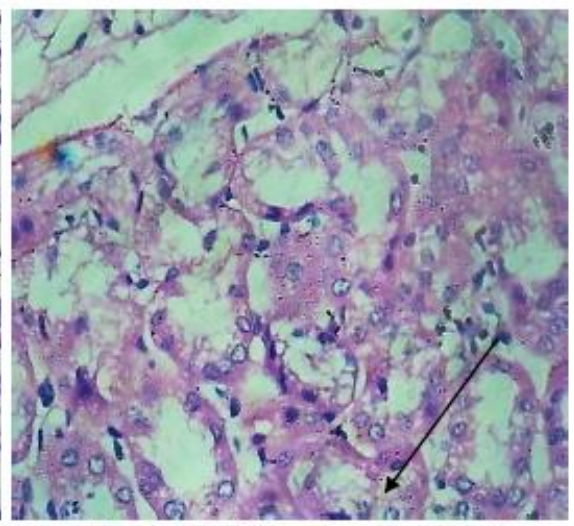

Fig: 1D(EECZB $100 \mathrm{mg} / \mathrm{kg}+\mathrm{APAP})$

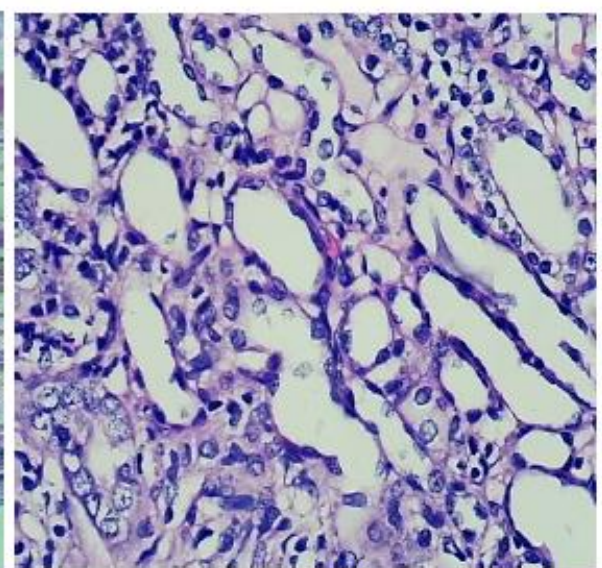

Fig: $1 \mathrm{~F}$ (Silymarin $(100 \mathrm{mg} / \mathrm{kg})+\mathrm{APAP})$

Figure 1: Histopathology of kidney showing normal PCT, DCT and Glumeruli (1A), acetaminophen induced Dilation of tubules , infiltration in bowman space, damage of podocytes, and infiltration of cells (1B), Normal renal architecture(1C), less neutrofil infiltration and less bowman space(1D), mild dilation, very less infiltration and mild podocyte damage(1E),Normal distal and proximal tubules, Bowman space, Glomeruli and infiltration of cells (1F)

\section{DISCUSSION}

Acetaminophen (APAP) is an effective, conventional, regularly used, universally accepted, over the counter,analgesic and antipyretic alternative to aspirin 33, but consumption of large dose or chronic use may cause hepatotoxicity and nephrotoxicity ${ }^{34}$. Drug induced nephrotoxicity can be assessed with alteration levels of serum urea and creatinine,also necrosis, thus the biochemical parameter serum creatinine and urea are used to explore and inspect nephrotoxicity caused by the drug in animals and man 35. Since creatinine is most derived endogenous source due to breakdown of tissue creatinine ${ }^{28}$. Thus serum urea concentration is considered as a better, 
stable and reliable renal function predictor than creatinine concentration in serum.

The possible protective role seen with EECZB regarding oxidative damage generated due to APAP induced nephrotoxicity were verified by histopatholoical examination of kidney. The substantial production of reactive NAPQI in presence of APAP over dose can cause covalant binding of macromolecules with cellular protein, leading to the interruption of homeostasis, apoptosis, tissue necrosis and finally organ dysfunction ${ }^{36}$. In present study the treatment with APAP alone resulted in changes of serum urea, creatinine and uric acid levels that were indicative of decrease glomerular filtration and disrupted kidney function 37,38. In renal diseases, the serum urea accumulate causes uraemiaas the serum urea formation outpace the rate of clearance ${ }^{39}$. The high blood urea level due to presence of APAP alone is suggests kidney injury. In this study APAP induced nephotoxicity showed a significant $(\mathrm{p}<0.001)$ increase in levels of urea and creatinine concentration whereas signficant $(p<0.001)$ decrease of uric acid and total protein levels in APAP treated rats group as compared to the rats who were not treated. Administration of EECZB at different dose $100 \mathrm{mg} / \mathrm{kg}, 200 \mathrm{mg} / \mathrm{kg}$, led to significantly $(\mathrm{p}<0.001, \mathrm{p}<0.01)$ decline in levels of urea and creatinine levels whereas uric acid and total protein significantly $(\mathrm{p}<0.001, \mathrm{p}<0.01))$ increased as compared to APAP treated group. Silymarin treated group showed significantly decrease in serum urea and creatinine levels but significantly increase in uric acid and total protein was seen in comparision to APAP treated group. However the urea, creatinine, uric acid and total protein did not differ significantly in normal as well as per se treated group (Table:1). As reprted by Azami et al. elevation in urea and creatinine levels is due to potentially strong correlation between nephrotoxicity and oxidative stress. The increase in $\mathrm{H}_{2} \mathrm{O}_{2}$ and $\mathrm{O}_{2}$ production changes the filtration surface area and thus an altered filtration coeficcient; both theses factors may decrease the glomerular filtration ultimatey leading to accumulation of urea and creatinine in blood 40 . Thus oxidative stress and lipid oxidation are primilaniry events leading to radicals generation during hepatic metaboism of APAP. Also a mechanism of formation of reactive oxygen species has been proposed by which many chemical can induce nephtotoxicity ${ }^{6}$. In hepatoxic conditions there is a decrease in total protein levels seen due to faulty protein biosynthesis in liver, similarly the acetaminophen induced nephrotoxic condition in rats also creates similar situations and that gets normalized after treated with EECZB, advocating its nephroprotective activity ${ }^{41}$. Previous studies reported that overdoe of acetaminophe nmay lead to increase in the lipid peroxidation and suppress the antioxidant defence mechanism in renal tissue ${ }^{42}$. In current study show that the administration of APAP dose resulted in significant $(\mathrm{p}<0.01, \mathrm{p}<0.001)$ decreased in superoxide dismutase, catalase and reduced glutathione activity when compare to normal control rats, due to inactivation of antioxidative enxymes. When rats was treated with EECZB $(100 \mathrm{mg} / \mathrm{kg})$ the reduction of superoxide dismutase, catalase and reduced glutathione activity were significantly $(\mathrm{p}<0.01, \mathrm{p}<0.001, \mathrm{p}<0.01)$ increased when compared with APAP treated rats. When rats was treateed with EECZB $(200 \mathrm{mg} / \mathrm{kg})$ the reduction of superoxide dismutase, catalase and reduced glutathione activity were also significantly $(\mathrm{p}<0.001, \mathrm{p}<0.001, \mathrm{p}<0.001)$ increased when compared with APAP treated rats. When compared with APAP treated group the superoxide dismutase, catalase and reduced glutathone were significantly $(\mathrm{p}<0.001)$ decrease in silymarin treated rats, However there was no significant difference in superoxide dismutase, catalase and reduced glutathione in normal as well as perse treated group (Table:2). Demirbag et al. has previously observed in their study a significant decreased in level of superoxide dismutase, catalase and reduced glutathione after acetaminophen overdose but increased lipid peroxidation and inactivation of the antioxidant enzymes ${ }^{43}$. In addition during kidney damage superoxide redicals are produced at site of damage and modulation of superoxide dismutase and catalase takes place resulting in loss of activity and accumulation of superoxide radical which causes kidney damage ${ }^{44}$. In a previous study, it has been reported that acetaminophen overdose caused a significant decrease in serum glutathione concentration. Intracellular glutathione play a crucial role in detoxification of acetaminophen and prevention of acetaminophen induced toxicity in liver and kidney 45,46 . Acetaminophen metabolism pathway during toxicity is dependent on cytochrome-450 due to saturation of glucuronidation and sulfation pathways thus forming an intermediate NAPQI in excess which leads to its conjugated with glutathione to detoxify this product with consequent exhaustion of cellular glutathione reverse. At sufficient high doses glutathione is reduced leaving NAPQI free and bind covalently and irreversibly to critical cellular protein ultimately causing cellular necrosis ${ }^{47}$. The histopathological findings were also in accordance with biochemical results demonstrating well preserved glomeruli, surrounded by Bowman capsule with mild swollen tubules (Figure:1). Most of the drug induced renal injuries affect the proximal tubules, glomerulus and distal part of the nephron 48 . The administration of APAP alone caused severe dilation of tubules, infiltration in bowman space, damage of podocytes, and infiltration of cells where as Ethanolic extract of Cinnamomum zeylanicum bark treatment at different dose $100 \mathrm{mg} / \mathrm{kg}, 200 \mathrm{mg} / \mathrm{kg}$, result in dose dependent nephroprotective against APAP induced nephrotoxicity. The results of the pesent study summarizes that EECZB has the ability to protect kidney damage caused by acetaminophen and might have a potential therapeutic effect for acetaminophen induced nehrotoxicity. The previous phytochemical studies showed the presence of different phytochemicals such as alkaloid, flavonoids, saponin and triterpenoid which are supposed to be responsible for its protective activity 49,25 .

\section{CONCLUSION}

In conclusion the administration of acetaminophen resulted in impairement of renal functional marker and histopathological alterations in rats kidney. Treatment with ethanolic exttract of Cinnamomum zeylanicum bark (EECZB) lead to significant restoration of biochemical parameter in acetaminophen treated rats.This beneficial effects of Cinnamomum zeylanicum bark may be atributed to the amelioration of the renal function. The findings of the present study suggests that Cinnamomum zeylanicum bark might be a potential nephroprotective agent against renal toxicity caused by acetaminophen.

\section{REFERENCES}

1. Afroz, R. Tanvir EM, Hossain MF et al. Protective effect of Sundarban honey against acetaminophen-induced acute hepatonephrotoxicity in rats. Evidence-Based Complementary and Alternative Medicine 2014; 1-10.

2. Elkarib Abbas 0. Inpact of dehydroepiandrosterone in prevention of paracetamol induced nephrotoxicity in rats. American Medical Journal 2014; 5(1):16-27

3. Sharma Anjali, Makwana Mukesh, Rathore HS. Will herbal paracetamol combination drug prevent both liver and kidney disease? Result and possibilies. Ethanobotanical Leaflets 2008; 12:286-298 
4. Ozkaya O, G Genc, K Bek and Y Sullu. A case of acetaminophen renal failure without liver damage in child. Renal failre 2010; 32:1125-1127

5. Frouad AA, Yacoubi MT, Bidawy HE. Therapeutic potential of hemin in acetaminophen nephrotoxicity in rats. Environmental Toxicology and Pharmacology 2009; 27:277282

6. Palani S, Raja S, Kumar RP, Parameswaran P, Kumar BS Therapeutic efficacy of Acorus calamus on acetaminophen induced nephrotoxicity and oxidative stressin male albino rats. Acta Pharmaceutica sciencia 2010; 52:89-100.

7. Bonkovsky HL, Kane RE, Jones DP, Galinsky RE, and Banner B. Acute hepatic and renal toxicity from low doses of acetaminophen in the absence of alcohol abuse or malnutrition: evidence for increased susceptibility to drug toxicity due to cardiopulmonary and renal insufficiency. Hepatology 1994; 19: 1141-1148.

8. Karthivashan Govindaran, Kura Aminu Umar, Arulselvan Palanisamy, Isa Norhaszalina Md and Fakurazi Sharida. The modulatory effect of moringa oleifera leaf extract on endogenous antioxidant system and inflammatory marker in an acetaminophen induced nephrotoxic mice model. Peer J 2016: 1-18.

9. Jones AF and Vale JA. Paracetamol poisoning and the kidney. Journal of Clinical Pharmacy and Therapeutics 1993; 18(1):58.

10. Moller-hartmann W, Siegers CP. Nephrotoxicity of paracetamol in rat- mechanism and therapeutic aspects. Journal of applied Toxicology 1991; 11: 141-146.

11. Nelson SD. Molecular mechanisms of hepatotoxicity caused by acetaminophen. Seminars in Liver Diseases 1990; 10:267-78.

12. Newton J, Hoefle D, Gemborys M, Mugede G, and Hook J. Metabolism and excretion of a glutathione conjugate of acetaminophen in the isolated rat kidney. Journal of Pharmacology and Experimental Therapeutics 1986; 237:519-24.

13. Richie Jr, J.P., C.A. Long, and T.S. Chen. Acetaminopheninduced depletion of glutathione and cysteine in aging mouse kidney. Biochemical Pharmacology1992; 44:129-35.

14. Eguia I, Materson B. acetaminophen related acute renal failure without fulminant liver failure. Pharmacotherapy1997; $17: 363-370$

15. Jones $\mathrm{AL}$ and Prescott LF. Unusual com placation of paracetamol poisoning. Quarterly journal of Medicine 1997; 90:161-168

16. Mollazadeh Hamid, Hosseinzadeh Hossein. Cinnamon effect on metabolic syndrome: A review based on its mechanism. Iranian journal of basic medical science 2016; 19:1258-1270

17. Kamal Rai Aneja, Radhika Joshi, Chetan Sharma. Antimicrobial activities of dalchini (Cinnamomum Zeylanicum) bark extract on some dental caries pathogens. Journal of Pharmacy research 2009: 2(9):1387-1390.

18. Marriapan PM, Sabesan G, Koilpillai B, Janakiraman S, Sharma NK. Chemical characterization and antigungal activity of methanolic extract of cinnamomum verum J. presl against malassezia spp. Pharmacognosy Journal 2013; 5:17-204

19. Uma B, Prabhkar K, Rajendran S, Lakshmi Sarayu. Studies on GC/MS spectroscopic analysis of some bioactive antimicrobial compounds from cinnamomum zeylanicum. Journal of medicinal plants 2009; 8((31):125-131

20. Vyas P, Suthar A, Patel D, Dayma P, Raval J and Joshi DK. Antimicrobial activity of extract of Cinnamomum zeylanicum bark and its combination with antibiotics against various microorganisms. Journal of Chemical and Pharmaceutical Researsch, 2005; 7(4):68-70

21. Rajendran A, Khan MR, Selvam D and Thangaraj V. Pharmacognosy profile and phytochemical analysis of Cinnamomum zeylanicum bark extract.A journal of Nehru art and science college 2017; 5(1):33-39

22. Parekh J, Karathia N, Chanda S. Evaluation of antibacterial activity and phytochemical analysis of Bauhinia variegata $\mathrm{L}$. bar. African Journal of biomedical and reseach 2006; 9:53-56

23. Evans MC: Treas and Evans Pharmacognosy, $15^{\text {th }}$ edition, Elsevier Publication, 2005; New Delhi, 191-393

24. OECD (Organization for economic Co-operation and development) Guideline 423. December 2001. Acute Oral Toxicity. Revised document
25. Parameshappa B, Basha MSA, Sen S, Chakkraborty R, Kumar GV, Sagar GV, Sowmya L, Raju KK, Kumar PKR, Lakkshmi AVSM. Aectaminophen induced nephrotoxicity in rats: Protective role of Cardiospermum halicabum. Pharmaceutical Biology 2012; 2:247-253

26. Ezeonwu VU, Dahiru D. Protective Effect of Bi-Herbal Formulation of Ocimum gratissimum and Gongronema latifolium Aqueous Leaf Extracts on Acetaminophen-induced Hepato-Nephrotoxicity in Rats. American Journal of Biochemistry 2013; 3(1):18-23

27. Nwachoo Ndidi, Essien Ea Bassey, Ayalogu Edward Obiozo. Effect of aframomun Chrysanthum Seed aqueous Extract against Acetaminophen induced liver toxicity in rats. Advances in Biochemistry 2019; 7(1):1-4.

28. Palani S, Raja S, Kumar RP, Jayaumari SP, Kumar BS Therapeutic efficacy of Pimpinella tirupatiensis on acetaminophen induced nephrotoxicity and oxidative stress in male albino rats. International journal of PharmaTech research 2009; 1(3):925-934

29. Okokon JE, Joseph OS, Umoh EE. Hepatoprotective activity of the extract of Homalium letestui stem aganst paractamol induced liver injury. Avicenna journal of phytomedicine 2017;7(1):27-36

30. Haque, M.R., Ansari, H.S. Anti-obesity effect of arq zeera and its main components thymol and cumin aldehyde in high fat diet induced obese rats. Drug Res. 2018; 68, 637-647.

31. Haque, M.R., Ansari, S.H. Aromatic aldehyde compound cuminaldehyde protects nonalcoholic fatty liver disease in rats feeding high fat diet. Hum. Exp. Toxicol. 2019; 38, 823832.

32. Haque, M.R., Ansari, S.H., Najmi, A.K., Ahmad, M.A. Monoterpene phenolic compound thymol prevents high fat diet induced obesity in murine model. Toxicol. Mech. Methods. 2014; 24, 116-123.

33. Adeneye AA, Benebo AS. Protective effect of aqueous leaf and seed extract phyllanthus amarus on gentamicin and acetaminophen induced nephrotoxic rats. Journal of Ethnopharmacology 2008; 118:318-323

34. Vouffo Edwige Y, Donfack Flaure M, Temdie Romeo J, at al.Hepato-nephroprotective and antioxidant effect of stem bark of Allanblackia gabonesis aquesous extract against acetaminophen induced liver and kidney disorder in rats. Journal of experimental and Integrative Medicine 2012; 2(4):337-344.

35. Adelman RD, Spangler WL, Beasom F, Ishizaki G, Conzelman GM. Furasemide enhancement of nelticimin nephrotoxicity in dogs. Journal of antimicrobial chemotherapy 1981; 7:431-435

36. Paul Sudip, Islam Md Ainul, Tanvir EM et al. Satkara (citrus macroptera) fruit protest against acetaminophen induced hepatorenal toxicity in rats. Evidence-Based Complementary and Alternative Medicine 2016: 1-11.

37. Ali Abeer R. Abd and Ismail Sajida H. the protective effect of honey against amikacin induced nephrotoxicity in rats. Iraqi Journal of Pharmaceutical science 2012; 21(2):85-93

38. Ali BH, Ismail TH, Basheer AA. Sex related differences in the susceptibility of rat to gentamicin nephrotoxicity: influence of gonadectomy and hormonal replacement therapy. Indian journal of Pharmacology 2001; 33:369-373.

39. Adeneye A, Olagunju J, Benebo AS et al., Nephroprotective effect of the aqueous root extract of Harungans madagascariensis(L.) in acute and repeated dose acetaminophen renal injured rats," international journal of applied research in Natural products 2008; 1(1):6-14

40. Ajami M, Eghtesadi S, Pazoki-Toroudi H, Habibey R. and Ebrahimi SA. Effect of Crocus sativus on gentamicin induced nephrotoxicity. Biol Res 2010; 43:83-90.

41. Kumar SS, Kumar BR, Mohan GK. Hepatoprotective effect of Trichosanthes cucumerina var.cucumerina (L). on carbon tetrachloride induced liver damage in rats. Journal of Ethnopharmacology 2009; 123:347-350.

42. Ghosh A, and Sil PC. Antioxidative effect of protein from cajamus indicus L. against acetaminophen indued hepatonephrotoxicity. Biocem. Mol. Bio 2007; 40:1039-1049

43. Demirbag S, Usyal B, Guven A, Cayci T, Ozler M, and Ozcan A. effect of medical zone therapy on acetaminophen induced nephrotoxicity in rats. Renal failure 2010; 32:493-499.

44. Ramadan BK, Schaalan MF. The Renoprotective Effect of Clover Flowers Honey on Paracetamol - Induced 
Nephrotoxicity in Adult Male Albino Rats. Life Science Journal 2011; 8(3):589-596

45. Palani, S, Raja S, Kumar NS, Kumar B Senthil. Nephroprotective and antioxidant activity of salacia oblonga on acetaminophen induced toxicity in rats. Natural product research 2011; 25(19):1876-1880

46. Roberts D and Buckley N. Pharmacokinetic considerations in clinical toxicology: Clinical Applications. Clinical Pharmacokinetic 2007; 46(11):897-939.

47. James L, McCullough S, Lamps L and Hinson J. effect of Nacetylcysteine on acetaminophen toxicity in mice; relationship to reactive nitrogen and cytokine formation. Toxicological Science 2003; 75(2):458-467

48. Nashar K and Egan B. "Relation between chronic kidney disease and metabolic syndrome: current perspective," Diabetes metabolic syndrome and obesity: Target and Therapy 2014; 7:421-435.

49. Balakumar P, Rohilla A, Thangathirupathi A. Gentamicin induced nephrotoxicity: Do we have a promising therapeutic approach to blunt it? Pharmacol Res 2010; 62:179-186. 